Rev. Bras. Saúde Prod. Anim., Salvador, v.16, n.4, p.839-849 out../dez.., 2015 http://www.rbspa.ufba.br

\title{
Silagem de resíduo da extração de amido da mandioca em substituição ao milho moído da ração para ovinos
}

\author{
Silage from residue from extraction of cassava starch in substitution of ground corn in \\ sheep feed
}

\author{
GONÇALVES, João Arlindo Gouveia ${ }^{1}$; ZAMBOM, Maximiliane Alavarse ${ }^{1}$; \\ FERNANDES, Tatiane ${ }^{2 *}$; TININI, Rodrigo Cesar dos Reis ${ }^{1}$; SCHIMIDT, Emerson \\ Luís $^{1}$; CASTAGNARA, Deise Dalazen ${ }^{3}$; CANABARRO, Luan de Oliveira ${ }^{4}$; CRUZ, \\ Eduardo Augusto da ${ }^{5}$
}

\footnotetext{
${ }^{1}$ Universidade Estadual do Oeste do Paraná, Centro de Ciências Agrárias, Marechal Cândido Rondon, Paraná, Brasil.

${ }^{2}$ Universidade Federal de Lavras, Departamento de Zootecnia, Lavras, Minas Gerais, Brasil.

${ }^{3}$ Universidade Federal do Pampa, Departamento de Medicina Veterinária, Uruguaiana, Rio Grande do Sul, Brasil.

${ }^{4}$ Universidade Federal de Santa Catarina, Departamento de Zootecnia, Florianópolis, Santa Catarina, Brasil.

${ }^{5}$ Universidade Federal do Rio Grande do Sul, Departamento de Zootecnia, Porto Alegre, Rio Grande do Sul, Brasil.

*Endereço para correspondência: tati-_-tati@hotmail.com
}

\section{RESUMO}

Com objetivo de avaliar o efeito da substituição do milho grão moído pela silagem de resíduo da extração de amido da mandioca, em dietas para ovinos em confinamento, foi mensurado o consumo, a digestibilidade da matéria seca (MS) e dos nutrientes, e o pH ruminal. Foram utilizados cinco ovinos, canulados, distribuídos em delineamento de quadrado latino $(5 \times 5)$, composto de cinco animais, cinco dietas e cinco períodos experimentais de 21 dias cada, em um total de 105 dias de experimento. Os tratamentos foram diferentes níveis de substituição $(0,25,50,75$ e $100 \%$ ) do milho pela silagem de resíduo da extração de amido da mandioca. Os níveis de substituição interferiram de forma significativa, obtendo variação cubica para a ingestão de MS, proteína bruta $(\mathrm{PB})$, matéria orgânica $(\mathrm{MO})$, extrato etéreo (EE) e carboidratos totais (CT), e efeito quadrático para a ingestão de fibra em detergente neutro (FDN) e fibra em detergente ácido (FDA). Porém não houve diferenças significativas na digestibilidadede nutrientes conforme a substituição do milho pela silagem de resíduo da extração de amido da mandioca, assim como não interferiram nos valores de $\mathrm{pH}$ ruminal. Recomenda-se a substituição de $75 \%$ do milho pela silagem de resíduo da extração de amido da mandioca.

Palavras-chave: consumo, nutrienes, resíduos

\section{SUMMARY}

With aimto evaluate the effect of replacing the ground grain corn for silage of waste resulting from the extraction of cassava starch in diets for sheep in confinement, was measured the consumption, the digestibility of dry matter and nutrients, and the rumen $\mathrm{pH}$. Were used five cannulated sheep, distributed in outline Latin square ( $5 \times 5)$, composed of five animals, five diets and five experimental periods of 21 days, for a total of 105 days of experiment. The treatments were different levels of substitution $(0,25,50,75,100 \%)$ of maize for silage of waste resulting from the extraction of cassava starch. The replacement levels obtained significant difference, obtaining cubic variation for the intake of dry matter (DM), crude protein (CP), organic matter (OM), ether extract (EE)and total carbohydrates (TC), and quadratic effect for neutral detergent fiber (NDF) and acid detergent fiber (ADF). But there were not significant differences in nutrient digestibility as the substitution of corn for silage of waste resulting from the extraction of cassava starch intake as well as not interfered in ruminal $\mathrm{pH}$ values. It is recommended the replacement of corn for silage $75 \%$ of residue of cassava starch extraction.

Keywords: consumption, nutrients, residues 
Rev. Bras. Saúde Prod. Anim., Salvador, v.16, n.4, p.839-849 out../dez.., 2015 http://www.rbspa.ufba.br

\section{INTRODUÇÃO}

O rebanho nacional de ovinos apresentou um aumento de $24,33 \%$ no período de 2006 a 2014, (IBGE, 2014). Com o aumento da produção há a necessidade de maiores pesquisas com relação às tecnologias de produção, como a busca por alimentos alternativos, que permite a obtenção de maior rentabilidade. Os ovinos, assim como os demais ruminantes possuem particularidades em seu sistema digestivo tornando-os capazes de transformar resíduos agroindustriais em alimentos de alta qualidade, como leite e carne (PEREIRA et al., 2010). Da mesma forma que possibilita redução de resíduos agroindustriais, que seriam descartados sem tratamento, resultando em danos ao meio ambiente (MELO et al., 2011).

Os subprodutos do processamento da mandioca destacam-se como substitutos energéticos mais baratos para formulação de rações para ruminantes, uma alternativa viável, pois possui valor nutritivo semelhante ao do milho (RAMALHO et al., 2006). O resíduo úmido da extração do amido apresenta elevada quantidade de carboidratos não fibrosos, com predominância do amido e baixo percentual de proteína, característica de todos os resíduos do processamento da mandioca (RAMALHO et al., 2006), sendo este amido mais facilmente degradado em relação ao milho, devido ao baixo teor de amilose (SVIHUS et al., 2005).

O resíduo da extração de amido da mandioca (REAM) é obtido a partir da extração de amido da mandioca por via úmida. De acordo com Jasko et al. (2011), o teor de umidade do bagaço que sai do processo é frequentemente superior a $80 \%$, dificultando a logística de transporte e armazenamento, pois o material é altamente perecível. A ensilagem é um processo eficiente para a armazenagem do resíduo de fécula de mandioca evitando assim perdas por degradação (GONÇALVES et al., 2014).

É fundamental conhecer as características do alimento, permitindo o estabelecimento de critérios para sua inclusão nas dietas dos animais (ABRAHÃO et al., 2006a). Embora os ruminantes tenham o ambiente ruminal a seu favor, que possibilita a utilização eficiente dos mais diversos alimentos, este mesmo ambiente pode ser sensivelmente afetado por alterações na dieta. Neste contexto, o objetivo deste estudo foi avaliar o efeito da substituição do milho grão moído pela silagem de resíduo da extração de amido da mandioca (SREAM), em dietas para ovinos em confinamento, mensurando o consumo, a digestibilidade de matéria seca e nutrientes, e o $\mathrm{pH}$ ruminal.

\section{MATERIAL E MÉTODOS}

Foram utilizados cinco ovinos da raça Santa Inês, castrados, canulados no rúmen, com peso corporal de 51,5 \pm $10,6 \mathrm{~kg}$. Durante o período experimental os animais foram alojados individualmente em baias cobertas e suspensas dotadas de piso ripado de madeira, bebedouro e comedouro individual.

O delineamento experimental adotado foi em quadrado latino $5 \times 5$, com cinco animais, cinco tratamentos e cinco períodos experimentais de 21 dias. Os tratamentos utilizados foram níveis de substituição do milho por silagem de resíduo úmido da extração de amido da mandioca (SREAM), $(0 \%, 25 \%, 50 \%$, $75 \%, 100 \%$ ). Os períodos experimentais foram subdivididos em 14 dias de 
Rev. Bras. Saúde Prod. Anim., Salvador, v.16, n.4, p.839-849 out../dez.., 2015 http://www.rbspa.ufba.br ISSN 15199940

adaptação e sete dias para coleta de dados, totalizando 105 dias de experimento.

A SREAM utilizada no experimento foi confeccionada a partir da ensilagem de REAM obtido em indústria processadora localizada no município de Marechal Cândido Rondon - PR. Após a obtenção do REAM o mesmo foi ensinado em manilhas de concreto com capacidade para $1000 \mathrm{~kg}$, onde permaneceu ensilado por um período de 45 dias. A abertura do primeiro silo coincidiu com o início do experimento. Por ocasião do início do experimento foi realizada amostragem e análises químicas da SREAM, da silagem de milho, do milho moído e do farelo de soja utilizados no experimento (Tabela 1). De posse da composição dos alimentos foram formuladas as dietas com os níveis de inclusão de SREAM em substituição ao milho respeitando-se a relação volumoso:concentrado de 60:40, para atender as exigências de animais em mantença. Por meio de análises laboratoriais foi estimada a composição química das dietas (Tabela 2).

Tabela 1. Composição bromatológica do milho, silagem de resíduo úmido da extração de amido da mandioca, silagem de milho e farelo de soja

\begin{tabular}{lcrrrrrr}
\hline \multirow{2}{*}{ Alimento } & MS & \multicolumn{1}{c}{ MO } & \multicolumn{1}{c}{ PB } & \multicolumn{1}{c}{ EE } & \multicolumn{1}{c}{ CT } & FDN & FDA \\
\cline { 3 - 8 } & $(\mathrm{g} / \mathrm{kg})$ & \multicolumn{7}{c}{$(\mathrm{g} / \mathrm{kg}$ de $\mathrm{MS})$} \\
Milho & 884,10 & 985,70 & 89,30 & 46,30 & 850,10 & 168,10 & 45,30 \\
REAM & 128,01 & 974,73 & 25,36 & 6,05 & 943,31 & 422,28 & 255,45 \\
SREAM & 186,80 & 973,90 & 28,70 & 5,60 & 939,60 & 434,60 & 251,70 \\
Silagem de milho & 322,70 & 960,10 & 86,20 & 24,70 & 849,20 & 605,70 & 256,90 \\
Farelo de soja & 886.00 & 939.90 & 510.00 & 7.90 & 422.00 & 130,57 & 106,54 \\
\hline
\end{tabular}

REAM $=$ resíduo úmido da extração de amido da mandioca; SREAM $=$ silagem de resíduo úmido da extração de amido da mandioca; $\mathrm{MS}$ = matéria seca; $\mathrm{MO}$ = matéria orgânica; $\mathrm{PB}=$ proteína bruta; $\mathrm{EE}=$ extrato etéreo; $\mathrm{CT}=$ carboidratos totais; $\mathrm{FDN}=$ fibra em detergente neutro; FDA $=$ fibra em detergente acido; NDT $=$ nutrientes digestíveis totais.

Diariamente todos os alimentos, foram pesados individualmente em balança eletrônica com precisão de $1 \mathrm{~g}$, homogeneizados manualmente $\mathrm{e}$ ofertados aos animais as 06:00 e 17:00 horas, na forma de mistura completa. Visando a não ocorrência de restrição alimentar e o monitoramento do consumo, as sobras foram pesadas diariamente mantendo-se uma proporção diária de sobras de $10 \%$ e assegurando um consumo equivalente a $2,0 \%$ do peso vivo.

Do $15^{\circ}$ ao $21^{\circ}$ dia do período experimental, as dietas experimentais de cada animal foram amostradas e homogeneizadas para obtenção de uma amostra composta por animal/período. No mesmo intervalo foi realizada a coleta total das fezes de cada animal com auxílio bolsas coletoras específicas, assim como coleta das sobras de cada animal. Logo após a coleta, as amostras foram pesadas em balança eletrônica com precisão de $1 \mathrm{~g}$, amostradas $(10 \%$ do total $)$ e imediatamente congeladas a $-18^{\circ} \mathrm{C}$.

Ao final do período de coleta as amostras foram homogeneizadas e présecas em estufa com ventilação forçada de ar, a $55^{\circ} \mathrm{C}$, durante 72 horas; e trituradas em moinho tipo Willey, com peneira com crivo de $1 \mathrm{~mm}$ de diâmetro. Nas amostras foram determinados os teores de matéria seca (MS), proteína bruta $(\mathrm{PB})$, extrato etéreo $(\mathrm{EE})$ e cinzas, segundo metodologias descritas em 
Rev. Bras. Saúde Prod. Anim., Salvador, v.16, n.4, p.839-849 out../dez.., 2015 http://www.rbspa.ufba.br ISSN 15199940

AOAC (2000); com a matéria orgânica (MO) estimada a partir da diferença entre a matéria seca e as cinzas. O teor de fibra em detergente neutro (FDN) e fibra em detergente ácido (FDA) foi determinado segundo metodologia de Van Soest et al. (1991).

Os carboidratos totais (CT) e os nutrientes digestíveis totais (NDT) foram estimados segundo as equações descritas por Sniffen et al. (1992): CT $(\%)=100-(\% \mathrm{~PB}+\% \mathrm{EE}+\%$ Cinzas $)$; $\mathrm{NDT}=\mathrm{PBD}+2,25 \times \mathrm{EED}+\mathrm{CTD} ;$ Onde: $\mathrm{PBD}=$ proteína bruta digestível, $\mathrm{EED}=$ extrato etéreo digestível CTD = carboidratos totais digestíveis.

Tabela 2. Composição percentual das dietas e composição química

\begin{tabular}{lrrrrr}
\hline \multirow{2}{*}{ Alimentos (g/kg da dieta) } & \multicolumn{5}{c}{ Níveis de substituição do milho por SREAM } \\
\cline { 2 - 5 } & \multicolumn{1}{c}{0} & \multicolumn{1}{c}{250} & 500 & \multicolumn{1}{c}{750} & 1000 \\
\hline Silagem de milho & 600,00 & 600,00 & 600,00 & 600,00 & 600,00 \\
SREAM & 0,00 & 73,00 & 140,80 & 204,00 & 254,00 \\
Milho & 300,00 & 219,30 & 141,10 & 68,20 & 0,00 \\
Farelo de soja & 96,00 & 104,02 & 114,60 & 124,30 & 142,20 \\
Mineral* & 04,00 & 03,50 & 03,50 & 03,50 & 03,80 \\
\hline Composição & & & & & 435,20 \\
\hline MS (g/kg) & 610,70 & 568,10 & 516,40 & 467,60 & 430,60 \\
MO (g/kg MS) & 909,40 & 913,10 & 917,00 & 926,90 & 928 \\
PB (g/kg MS) & 136,50 & 137,70 & 151,00 & 148,10 & 152,20 \\
EE (g/kg MS) & 33,60 & 29,90 & 24,60 & 19,40 & 16,80 \\
CT (g/kg MS) & 740,00 & 745,50 & 741,50 & 759,30 & 748,40 \\
FDN (g/kg MS) & 344,80 & 367,20 & 394,80 & 421,30 & 444,10 \\
FDA (g/kg MS) & 150,30 & 163,50 & 182,60 & 197,70 & 214,60 \\
NDT (g/kg MS) & 707,00 & 702,40 & 701,40 & 709,00 & 700,00 \\
\hline SREAM
\end{tabular}

SREAM = silagem de resíduo úmido da extração de amido da mandioca; $\mathrm{MS}=$ matéria seca $(\mathrm{g} / \mathrm{kg}) ; \mathrm{MO}$ : matéria orgânica $(\mathrm{g} / \mathrm{kg} \mathrm{MS}) ; \mathrm{PB}=$ proteína bruta $(\mathrm{g} / \mathrm{kg} \mathrm{MS}) ; \mathrm{EE}=$ extrato etéreo $(\mathrm{g} / \mathrm{kg} \mathrm{MS}) ; \mathrm{CT}=$ carboidratos totais $(\mathrm{g} / \mathrm{kg} \mathrm{MS}) ; \mathrm{FDN}=$ fibra em detergente neutro $(\mathrm{g} / \mathrm{kg} \mathrm{MS}) ; \mathrm{FDA}=$ fibra em detergente acido (g/kg MS); NDT = nutrientes digestíveis totais $(\mathrm{g} / \mathrm{kg} \mathrm{MS})$.

*Cálcio: $155 \mathrm{~g} / \mathrm{kg}$, fósforo: $65 \mathrm{~g} / \mathrm{kg}$, sódio: $115 \mathrm{~g} / \mathrm{kg}$, magnésio: $6 \mathrm{~g} / \mathrm{kg}$, enxofre: $12 \mathrm{~g} / \mathrm{kg}$, ferro: $1000 \mathrm{mg} / \mathrm{kg}$, manganês: $1400 \mathrm{mg} / \mathrm{kg}$, zinco: $6000 \mathrm{mg} / \mathrm{kg}$, cobre: $100 \mathrm{mg} / \mathrm{kg}$, cobalto: $175 \mathrm{mg} / \mathrm{kg}$, iodo: $175 \mathrm{mg} / \mathrm{kg}$, selênio: $27 \mathrm{mg} / \mathrm{kg}$

No $21^{\circ}$ dia do período experimental, nos horários $0,2,4,6$ e $8 \mathrm{~h}$ após a alimentação, de cada animal foi coletada uma amostra representativa de líquido do rúmen via cânula ruminal, a qual foi filtrada rapidamente em tecido de algodão para a obtenção de aproximadamente $200 \mathrm{~mL}$ de líquido ruminal. Neste determinou-se o $\mathrm{pH}$ com auxílio de potenciômetro digital. Uma alíquota de $50 \mathrm{~mL}$ foi acrescida de $1 \mathrm{~mL}$ de ácido sulfúrico 1:1 e congelada, para posterior determinação do nitrogênio amoniacal $\left(\mathrm{N}-\mathrm{NH}_{3}\right)$, conforme técnicas de Fenner (1965). Para os valores de $\mathrm{pH}$ e N-NH foi utilizada quadrado latino com parcelas subdivididas nos tempos de coleta.

Os dados foram analisados através da análise de variância, utilizando-se $\mathrm{o}$ Sistema de Análises Estatísticas e Genéticas programa (SAEG), desenvolvido pela Universidade Federal de Viçosa (UFV, 1997). Constatada a significância por meio de análise de 
Rev. Bras. Saúde Prod. Anim., Salvador, v.16, n.4, p.839-849 out../dez.., 2015 http://www.rbspa.ufba.br ISSN 15199940

variância, os dados foram comparados por meio de análise de regressão considerando os níveis de SREAM ( $0 \%$; $25 \% ; 50 \% ; 75 \%$ ou $100 \%$ ) ao nível de $5 \%$ de probabilidade.

\section{RESULTADOS E DISCUSSÃO}

O aumento de SRUFM na dieta de ovinos influenciou de forma significativa $(\mathrm{P}<0,05)$ a ingestão de matéria seca, apresentando variação cúbica, a partir deste resultado foi observado diferenças significativas para a ingestão dos demais nutrientes (Tabela 3). Na nutrição animal, o consumo é o fator que exerce o papel de maior importância, pois determina o nível de nutrientes ingeridos (FOTIUS et al., 2014).

A ingestão de MS foi superior ao predito pelo NRC (2007), que estima ingestão de aproximadamente $0,90 \mathrm{~kg}$ por dia, para animais em mantença de $51,5 \pm 10,6 \mathrm{~kg}$. As diferenças significativas $(\mathrm{P}<0,05)$ para a ingestão de $\mathrm{PB}, \mathrm{MO}, \mathrm{EE}, \mathrm{FDN}, \mathrm{FDA}$, CT e NDT devem-se à IMS, é provável que a variação na IMS e demais nutrientes pode ser explicada pelo mecanismo quimiostático, uma vez que o efeito de enchimento não foi o limitante para a IMS, pois o teor de FDN era inferior ao limite sugerido de 50 a $60 \%$ (SILVA, 2006). Quando ocorre o efeito quimiostático, a limitação na ingestão da dieta deve-se ao elevado conteúdo de energia da dieta. É possível que neste trabalho tenha ocorrido efeito de aditividade entre os ingredientes das dietas, podendo ocorrer melhora nos padrões de fermentação nos tratamentos com maiores quantidades de SREAM, resultando no maior consumo de MS.

Tabela 3. Ingestão de nutrientes em ovinos alimentados com dietas contendo níveis crescentes de silagem de resíduo da extração do amido da mandioca em substituição ao milho da ração

\begin{tabular}{|c|c|c|c|c|c|c|c|c|c|}
\hline \multirow{2}{*}{ Item } & \multicolumn{5}{|c|}{ SREAM } & \multirow{2}{*}{$\begin{array}{l}\text { Equação de } \\
\text { Regressão }\end{array}$} & \multirow{2}{*}{$\mathrm{R}^{2}$} & \multirow{2}{*}{$\mathrm{P}$} & \multirow{2}{*}{$\mathrm{CV}$} \\
\hline & $0 \%$ & $25 \%$ & $50 \%$ & $75 \%$ & $100 \%$ & & & & \\
\hline $\mathrm{IMS}^{1}(\mathrm{~kg} / \mathrm{dia})$ & 1,25 & 0,99 & 1,06 & 1,32 & 1,28 & 1 & 0,98 & 0,02 & 10,49 \\
\hline $\operatorname{IPB}^{2}(\mathrm{~kg} / \mathrm{dia})$ & 0,17 & 0,12 & 0,15 & 0,18 & 0,17 & 2 & 1,00 & $<0,01$ & 10,55 \\
\hline $\operatorname{IMO}^{3}(\mathrm{~kg} / \mathrm{dia})$ & 1,20 & 0,95 & 1,00 & 1,26 & 1,22 & 3 & 0,98 & $<0,01$ & 10,64 \\
\hline $\operatorname{IFDN}^{4}(\mathrm{~kg} / \mathrm{dia})$ & 0,50 & 0,42 & 0,49 & 0,61 & 0,64 & 4 & 1,00 & $<0,01$ & 9,62 \\
\hline $\operatorname{IFDA}^{5}(\mathrm{~kg} / \mathrm{dia})$ & 0,21 & 0,19 & 0,21 & 0,27 & 0,28 & 5 & 0,89 & 0,01 & 11,49 \\
\hline $\operatorname{IEE}^{6}(\mathrm{~kg} / \mathrm{dia})$ & 0,04 & 0,03 & 0,03 & 0,03 & 0,02 & 6 & 1,00 & $<0,01$ & 15,59 \\
\hline $\mathrm{ICT}^{7}$ (kg/dia) & 0,99 & 0,79 & 0,83 & 1,05 & 1,02 & 7 & 0,97 & $<0,01$ & 10,75 \\
\hline $\operatorname{INDT}^{8}(\mathrm{~kg} / \mathrm{dia})$ & 0,88 & 0,69 & 0,78 & 0,93 & 0,76 & 8 & 0,93 & 0,03 & 15,81 \\
\hline
\end{tabular}

${ }^{1}$ IMS = ingestão de matéria seca, $Y=0,010-0,0086 X+0,000074 X^{2}-0,0000033 X^{3} ;{ }^{2}$ IPB $=$ ingestão de proteína bruta, $\mathrm{Y}=0,1481-0,0015 \mathrm{X}+0,0000099 \mathrm{X}^{2}-0,000037 \mathrm{X}^{3} ;{ }^{3} \mathrm{IMO}=$ ingestão de matéria orgânica, $\mathrm{Y}=1,039-0,0082 \mathrm{X}+0,0000728 \mathrm{X}^{2}-0,0000032 \mathrm{X}^{3} ;{ }^{4} \mathrm{IFDN}=$ ingestão de fibra em detergente neutro $\mathrm{Y}=$ $0,494734-0,001948 \mathrm{X}+0,000033 \mathrm{X}^{2} ;{ }^{5} \mathrm{IFDA}=$ ingestão de fibra em detergente ácido, $\mathrm{Y}=0,2177-$ $0,00095 \mathrm{X}+0,000013 \mathrm{X}^{2} ;{ }^{6} \mathrm{IEE}=$ ingestão de extrato etéreo, $\mathrm{Y}=0,02708-0,00004138 \mathrm{X}+0,0000025 \mathrm{X}^{2}-$ $0,00000009329 \mathrm{X}^{3} ;{ }^{7} \mathrm{ICT}=$ ingestão de carboidratos totais, $\mathrm{Y}=0,86445-0,006651 \mathrm{X}+0,00006036 \mathrm{X}^{2}$ $0,000002534 \mathrm{X}^{3} ;{ }^{8} \mathrm{INDT}=$ ingestão de nutrientes digestíveis totais, $\mathrm{Y}=0,7768-0,006823 \mathrm{X}+0,0000227 \mathrm{X}^{2}-$ $0,000003215 \mathrm{X}^{3}$ 
Segundo Vieira et al. (2008), o uso de alimentos com elevado teor de umidade e de carboidratos não fibrosos pode reduzir o consumo de matéria seca devido a distúrbios digestivos. No entanto, esses efeitos negativos não foram observados no presente estudo, evidenciando o potencial de utilização da SREAM na alimentação de ruminantes, especialmente ovinos.

Neste trabalho foi observada uma variação cúbica, apresentando um pico de maior ingestão quando $75 \%$ do milho foi substituído pela SREAM, porém não houve grande variação nos tratamentos $0 \%, 75 \%$ e $100 \%$, sendo que o menor consumo foi observado no tratamento com $25 \%$ de SREAM. Diferentemente de Abrahão et al. (2006), utilizando resíduo úmido de mandioca, para a alimentação de tourinhos em terminação, não observou diferenças significativas no consumo de matéria seca em relação ao peso vivo.

O mesmo ocorreu com a IPB, onde houve um menor consumo no tratamento com 25 e $50 \%$, sendo que a variação entre os demais tratamentos foi menor. Lima et al. (2008), avaliando o efeito da inclusão de diferentes níveis $(0,5,10$ e $15 \%)$ de bagaço de mandioca à dieta de 12 vacas mestiças leiteiras Holandês $\mathrm{x}$ Zebu verificaram que o aumento do nível de inclusão de bagaço de mandioca houve aumento na IPB, devido ao maior consumo.

As diferenças observadas na ingestão de FDN e FDA foram influenciadas pela IMS, assim como pela composição das dietas, uma vez que conforme o aumento da substituição do milho pela SREAM ocorreu aumento nos teores de FDN e FDA da dieta. As alterações observadas para IEE são explicadas pela variação observada no consumo, resultando em uma variação cubica. A ICT e a INDT variou de uma maneira similar às demais ingestões principalmente por estar ligada aos níveis de EE e PB da dieta.

Os coeficientes de digestibilidade aparente (CD) da MS, MO, PB, EE, CT, FDN e FDA das dietas utilizando SREAM em substituição do milho, não apresentaram diferença significativas (Tabela 4). A substituição do milho pela SREAM não influenciou na digestibilidade da MS das dietas, sendo determinado valor médio de 72,77, superior ao observado por Abrahão et al. (2006), na substituição do milho pelo resíduo úmido de mandioca em dieta de tourinhos em terminação encontrou valores médios de $65,42 \%$ para MS.

Ramos et al. (2007), verificaram que a substituição do milho por bagaço de mandioca não alterou os coeficientes de digestibilidade de MS, MO, FDN e FDA. Segundo Dias et al. (2008), o aumento do bagaço de mandioca interferiu no consumo de matéria seca digestível, matéria orgânica digestível e fibra em detergente neutro digestível, em função do aumento da proporção de concentrado na dieta, para suprir as exigências dos animais, influenciando a digestibilidade da FDN.

Os valores de coeficientes de digestibilidade para $\mathrm{MO}, \mathrm{PB}$ na substituição do milho pela SREAM não foram significativos. Dias et al. (2008), também não encontraram diferenças para digestibilidade da MS, MO, e PB na inclusão de bagaço de mandioca em novilhas leiteiras, 3/4 Gir x 1/4 Holandês. Não houve efeito da substituição do milho pela SREAM sobre o CDFDN e CDFDA $(61,85$ e $42,27 \%$ respectivamente). Dias et al. (2002) verificaram efeito linear decrescente na digestibilidade do FDN trabalhando com bagaço de mandioca com aumento de sua inclusão em substituição ao milho em virtude do aumento da relação de concentrado da dieta reduzindo o $\mathrm{pH}$ e afetando as bactérias ruminais. Já neste 
Rev. Bras. Saúde Prod. Anim., Salvador, v.16, n.4, p.839-849 out../dez.., 2015 http://www.rbspa.ufba.br ISSN 15199940

trabalho não houve diferença significativa no $\mathrm{pH}$ ruminal entre os tratamentos (Figura 1) a um nível que alterasse a flora ruminal.

O CDEE foi semelhante entre os tratamentos, não apresentando diferenças estatísticas com valor médio de $82,78 \%$ que são superiores aos citados por
Abrahão et al. (2006), em dieta de tourinhos com CDEE médio de 67,72\%. Dias et al. (2008) obteve redução de forma linear com o aumento da inclusão do bagaço de mandioca na dieta de novilhas leiteiras que ele atribuiu a depressão do $\mathrm{pH}$ ruminal.

Tabela 4. Coeficiente de digestibilidade de nutrientes e valor dos nutrientes digestíveis totais da dieta experimental de ovinos alimentados com silagem de resíduo úmido de fécula de mandioca (SREAM) em substituição ao milho moído da ração

\begin{tabular}{|c|c|c|c|c|c|c|c|c|c|}
\hline \multirow{2}{*}{ Item } & \multicolumn{5}{|c|}{ SREAM } & \multirow{2}{*}{ Média } & \multirow{2}{*}{$\mathrm{R}^{2}$} & \multirow{2}{*}{$\mathrm{P}$} & \multirow{2}{*}{$\mathrm{CV}$} \\
\hline & $0 \%$ & $25 \%$ & $50 \%$ & $75 \%$ & $100 \%$ & & & & \\
\hline CDMS & 74,20 & 72,86 & 73,28 & 73,82 & 69,1 & 72,77 & NS & 0,30 & 5,236 \\
\hline CDMO & 75,41 & 74,36 & 74,59 & 75,19 & 71,08 & 74,23 & NS & 0,27 & 5,012 \\
\hline CDPB & 73,24 & 71,25 & 73,58 & 73,65 & 67,93 & 72,05 & NS & 0,19 & 5,875 \\
\hline CDFDN & 59,94 & 59,93 & 64,82 & 64,72 & 57,88 & 61,85 & NS & 0,54 & 10,543 \\
\hline CDFDA & 36,41 & 40,48 & 43,46 & 44,61 & 47,51 & 42,21 & NS & 0,37 & 23,214 \\
\hline CDEE & 86,53 & 85,19 & 83,69 & 81,79 & 74,71 & 82,78 & NS & 0,23 & 3,506 \\
\hline CDCT & 74,17 & 73,37 & 73,37 & 74,30 & 70,35 & 73,20 & NS & 0,24 & 5,270 \\
\hline NDT & 70,70 & 70,24 & 70,13 & 70,90 & 67,01 & 69,79 & NS & 0,38 & 3,788 \\
\hline
\end{tabular}

CDMS = coeficiente de digestibilidade da matéria seca (\%); CDMO = coeficiente de digestibilidade da matéria orgânica (\%); CDPB = coeficiente de digestibilidade da proteína bruta (\%); CDEE = coeficiente de digestibilidade do extrato etéreo (\%); CDFDN = coeficiente de digestibilidade da fibra em detergente neutro (\%); CDFDA = coeficiente de digestibilidade da fibra em detergente acido (\%); CDCT = coeficiente de digestibilidade dos carboidratos totais (\%); NDT = nutrientes digestíveis totais $(\%)$.

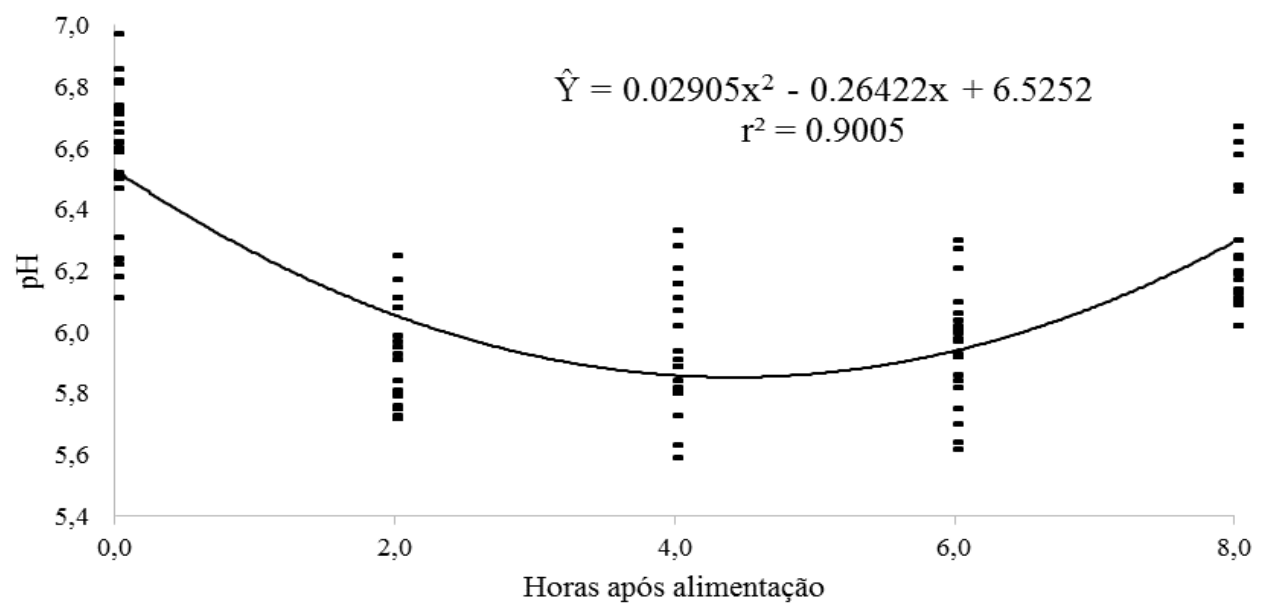

Figura 1. Variação do pH do líquido ruminal no período de cinco coletas a cada duas horas após o fornecimento de alimento 
Embora não tenha apresentado diferença significativa entre os tratamentos para o CDCT, observou-se uma pequena redução no tratamento com $100 \%$ de substituição do milho pela SREAM, isto pode estar relacionado à menor ingestão de $\mathrm{EE}$ na dieta em relação às outras substituições. De acordo com Caldas Neto et al. (2000), a composição do amido dessas duas fontes (SREAM e milho) são diferentes, o amido de mandioca é composto principalmente por cadeias de amilopectina, enquanto do milho tem menor proporção. Desta forma Abrahão et al. (2006) cita que em seu trabalho não houve alteração dos níveis de carboidratos não fibrosos, mas ocasionou a substituição dos carboidratos do milho pelos da mandioca.

Para os valores de $\mathrm{pH}$ não foram observadas diferenças significativas entre os tratamentos, sendo observado efeito semelhante para todos os tratamentos nas diferentes horas após a alimentação (Figura 1). Isto provavelmente ocorreu devido à formulação da dieta que era de $60 \%$ de volumoso e $40 \%$ de concentrado fornecido em dieta total.

No processo de fermentação ruminal o $\mathrm{pH}$ tem um papel fundamental na digestão dos alimentos. Uma variação de $\mathrm{pH}$ em que a atividade se mantém próxima do normal seria de 0,5 unidades, no entanto o $\mathrm{pH}$ ruminal pode variar de 5,5 a 7,2, com valores baixos de $\mathrm{pH}$ sendo detectados em intervalos de tempos curtos, após a alimentação dos animais com dietas ricas em concentrado (VALADARES FILHO \& PINA, 2006). No entanto a faixa ideal de digestão da fibra ocorre entre 6,7 e 7,1 (WANDERLEY et al., 2012), como podemos observar neste estudo osvalores se mantiveram abaixo da faixa de variação adequada para a digestão da fibra, ainda assim a digestão das frações fibrosas não foi prejudicada mantendo valores elevados.

Para os valores de $\mathrm{N}-\mathrm{NH}_{3}$ não foram observadas diferenças significativas entre os tratamentos, apenas nas horas após a alimentação, sendo observado efeito semelhante para todos os tratamentos (Figura 2). As alterações da concentração de $\mathrm{N}-\mathrm{NH}_{3}$ no fluido ruminal, podem ser decorrentes da variação observada para $\mathrm{o}$ $\mathrm{pH}$ do rúmen nas horas após a alimentação. Pois a amônia pode ser absorvida através da parede do rúmen, na sua forma não ionizada (NH3), mas não a sua forma ionizada (NH4+) que ocorre quando o pH está baixo (SANTOS \& PEDROSO, 2011).

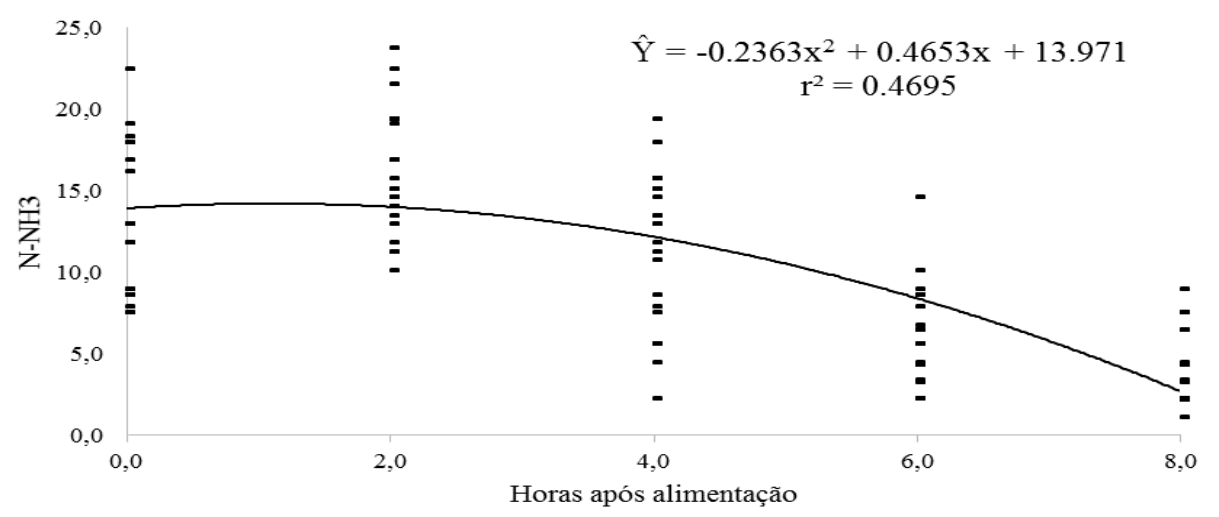

Figura 2. Variação do nitrogênio amoniacal $\left(\mathrm{N}-\mathrm{NH}_{3}\right)$ do líquido ruminal no período de cinco coletas a cada duas horas após o fornecimento de alimento 
Rev. Bras. Saúde Prod. Anim., Salvador, v.16, n.4, p.839-849 out../dez.., 2015 http://www.rbspa.ufba.br ISSN 15199940

Em dietas para ovinos, onde a relação volumoso concentrado está próxima a 40:60 recomenda-se a substituição de $75 \%$ do milho pela silagem de resíduo da extração de amido da mandioca, em função do aumento no consumo de matéria seca, não obtendo alterações na digestibilidade e $\mathrm{pH}$ ruminal.

\section{REFERÊNCIAS}

ABRAHÃO, J.J.S.; PRADO, I.N.; PEROTTO, D.; ZEOULA, L.M.; LANÇANOVA, J.A.C.; LUGÃO, S.M.B. Digestibilidade de dietas contendo resíduo úmido de mandioca em substituição ao milho para tourinhos em terminação.Revista Brasileira de Zootecnia, v.35, n.4, p.512-518, 2006.

ASSOCIATION OF OFFICIAL ANALYTICAL CHEMISTS - AOAC. Official methods of analysis. 17.ed. Arlington: AOAC Internacional, 2000.

CALDAS NETO, S.F.; ZEOULA, L.M.; BRANCO A.F.; IVANOR NUNES DO PRADO, I.N. do; SANTOS, G.T. dos; FREGADOLLI, F.L.; KASSIES, M.P.; DALPONTE, A.O. Mandioca e resíduos das farinheiras na alimentação de ruminantes: digestibilidade total e parcial. Revista Brasileira de Zootecnia, v.29, n.6, p.2099-2108, 2000.

DIAS, A.M.; SILVA, F.F.; VELOSO, C.M.; IATVO, L. Digestibilidade dos nutrientes do bagaço de mandioca em dietas de novilhas leiteiras. Arquivos Brasileiros de Medicina Veterinária e Zootecnia,v.60,p.996-1003, 2008.

FENNER, H. Method for determining total volatile bases in rumen fluid by steam distillation. Journal Dairy of Science, v.48, p.249-251, 1965.
FOTIUS, A.C.A.; FERREIRA, M.A.; VÉRAS, A.S.C.; SALLA, L.E.; SOUZA, A.R.D.L.; BISPO, S.V. Estratégia de nutrientes para ovinos em distintas sequências de fornecimento alimentar em dieta a base de palma forrageira. Revista Brasileira de Saúde e Produção Animal [online], v.15, n.2, p.504-516, 2014.

GONÇALVES, J.A.G.;

MAXIMILIANE, M.A.; FERNANDES, T.; MESQUITA, E.E.; SCHIMIDT, E.; JAVORSKI, C.R.; CASTAGNARA, D.D. Composição químico-bromatológica e perfil de fermentação da silagem de resíduo úmido de fécula de mandioca.

Bioscience Journal, v.30, n.2, p.502-511, 2014.

INSTITUTO BRASILEIRO DE GEOGRAFIA ESTATÍSTICA - IBGE. Pesquisa Pecuária Municipal, v.42, p.1-39, 2014. Disponível em: $<$ http://www.ibge.gov.br/biblioteca/visu alizacao/periodicos/84/ppm_2014_v42 br.pdf>. Acesso em: 15 jul. 2014.

JASKO, A.C.; ANDRADE, J.; CAMPOS, P.F.; PADILHA, L.; PAULI, R.B. de; QUAST, L. Caracterização físico-química de bagaço de mandioca in natura e após tratamento hidrolítico.

Revista Brasileira de Tecnologia Agroindustrial, v.5, p.427-441, 2011. Supl.

LIMA, L.P.; VELOSO, C.M.; SILVA, F.F. L.P.; BONOMO, P.; PINHEIRO, A.A.; DUTRA, G.S.; PEREIRA JÚNIOR, I.G.; VELOS, J.M.C. Bagaço de mandioca (Manihotesculenta, Crantz) na dieta de vacas leiteiras: consumo de nutrientes. Arquivo Brasileiro de Medicina Veterinária e Zootecnia, v.60, n.4, p.1004-1010, 2008. 
Rev. Bras. Saúde Prod. Anim., Salvador, v.16, n.4, p.839-849 out../dez.., 2015 http://www.rbspa.ufba.br ISSN 15199940

MELO, P.S.; BERGAMASCHI, K.B.; TIVERON, A.P.; MASSARIOL, A.P.; OLDONI, T.L.C.; ZANUS M.C.; PEREIRA, G.E.; ALENCAR, S.M. de. Composição fenólica e atividade antioxidante de resíduos agroindustriais. Ciência Rural, v.41, n.6, p.1088-1093, 2011.

NATIONAL RESEARCH COUNCIL NRC. Nutrient Requirements of Poultry. Washington, DC: National Academy Press, 2007.

PEREIRA, E.S.; REGADAS FILHO, J.G.L.; ARRUDA, A.M.V. MIZUBUTI, I.Y.; VILLARROEL, A.B.S.; PIMENTEL, P.G.; CÂNDIDO, M.J.D. Equações do NRC (2001) para predição do valor energético de co-produtos da agroindústria no nordeste brasileiro.

Revista Brasileira de Saúde e Produção Animal [online], v.9, n.2, p.258-269, 2008.

RAMALHO, R.P.; FERREIRA, M.A.; VÉRAS, A.S.C.; LIMA, L.E.; ROCHA, V.R.R.A.Substituição do milho pela raspa de mandioca em dietas para vacas primíparas em lactação. Revista Brasileira de Zootecnia, v.35, n.3, p.1221-1227, 2006.

RAMOS, P.R. Utilização do bagaço de mandioca como alimento energético para bovinos. 2007. 105p. Dissertação (Mestrado) - Embrapa Semiárido / Faculdade de Agronomia, Universidade Federal do Rio Grande do Sul, Porto Alegre.

SANTOS, F A.P.; PEDROSO, A.M. Metabolismo de proteínas. In: BERCHIELLI, T.T.; PIRES, A.V.; OLIVEIRA, S.G. (Eds.). Nutrição de ruminantes. 2.ed. Jaboticabal: FUNEP, 2011. p.265-292.
SILVA, J.F.C. Mecanismos reguladores de consumo. In: In: BERCHIELLI, T.T.; PIRES, A.V.; OLIVEIRA, S.G. (Eds.). Nutrição de Ruminantes. Jaboticabal: FUNEP, 2006. p.57-78.

SNIFFEN, C.J.; O'CONNOR, J.D.; VAN SOEST, P.J.; FOX, D.G.; RUSSELL, J.B. A net carbohydrate and protein system for evaluating cattle diets: II. Carbohydrate and protein availability. Journal of Animal Science, v.70, n.11, p.3562-3577, 1992.

SVIHUS, B.; UHLEN, A.K.; HARSTAD, O.M. Effect of starch granule structure, associated components and processing on nutritive value of cereal starch: A review. Animal Feed Science and Technology, v.122, p.303320, 2005.

UNIVERSIDADE FEDERAL DE VIÇOSA - UFV. SAEG- Sistema para análises estatísticas e genéticas. Versão 7.1. Viçosa, MG: 1997. 150p.

VALADARES FILHO, S.C.; PINA D.S. Fermentação Ruminal. In: BERCHIELLI, T.T.; PIRES, A.V.; OLIVEIRA, S.G. (Eds.). Nutrição de ruminantes. 2.ed. Jaboticabal: FUNEP, 2006. P.151-178.

VAN SOEST, P.J.; ROBERTSON, J.B.; LEWIS, B.A. Carbohydrate metodology, metabolism, and nutritional implications in dairy cattle. Journal of Dairy Science, v.74, n.10, p.3583-3597, 1991.

VIEIRA, E.L.; BATISTA, A.M.V.; GUIM, A.; CARVALHO, F.F.R.; NASCIMENTO, A.C.O.; ARAÚJO, R.F.S. da S. ; MUSTAFA, A.F. Effects of hay inclusion on intake, total tract nutrient utilization and ruminal fermentation of goats fed spineless cactus (Opuntiaficusindica Mill) based diets. Animal Feed Science and Technology, v 141, n.3-4, p.199-208, 2008. 
Rev. Bras. Saúde Prod. Anim., Salvador, v.16, n.4, p.839-849 out../dez.., 2015 http://www.rbspa.ufba.br ISSN 15199940

WANDERLEY, W.L.; FERREIRA, M.A.; BATISTA, Â.M.V.; VÉRAS,

A.S.C.; BISPO, .V.; SILVA, F.M.;

SANTOS, V.L.F. Consumo,

digestibilidade e parâmetros ruminais em ovinos recebendo silagens e fenos em associação à palma forrageira.

Revista Brasileira de Saúde e

Produção Animal [online], v.13, n.2, p.444-456, 2012.

Data de recebimento: 16/09/2014

Data de aprovação: 04/11/2015 